\title{
APROXIMACIÓN AL ANÁLISIS DISCURSIVO EN LOS TEXTOS ESCOLARES DE QUÍMICA \\ Caso: Libro de Texto Química 4 de Maryori Serrano y José F. de Sanella
}

Pedro Certad: Universidad Metropolitana (Venezuela)

\section{Resumen}

El discurso ya a principios de la década de los 60 es analizado bajo métodos cualitativos que lo estudian sistemáticamente en sus formas tanto escritas como hablada enmarcándolo en una manera de uso de una lengua a través de cinco grandes estilos, los cuales según Silva (1997) son: a) analítico lingüístico, b) conversacional, c) cognitivo experimental, d) inteligencia artificial y informática y e) análisis crítico del discurso.

Es a través de su análisis que se posibilita la exploración de la gramática del texto, la conversación, la estilística, la retórica, la argumentación, la narrativa, los géneros y otras categorías que permiten tener una amplia visión del discurso en estudio y acerca a la profundización y comprensión de hechos que, de manera descontextualizada y aislada, no otorgarían una información fundamental el investigador. (Silva, 1997; Constantino, 2002)

Es por lo anteriormente expuesto, que se cree conveniente hacer una revisión aproximada de los textos escolares a partir del análisis del discurso expuesto en los mismos, en este caso de Química de cuarto año de educación media general (EMG) del sistema educativo venezolano ya que, permitirá al investigador comprender el texto escolar más allá de un grupo de oraciones, definiciones y relatos. El análisis discursivo debe ayudar a entender el texto como un todo objeto de la reflexión, mediador entre el docente y el alumno y, trascendental al hecho de difundir saberes (Ramírez, 2003).

El texto escolar elegido para esta aproximación fue escrito por Maryori Serrano y José Fabián Sanella, ambos venezolanos, profesores en la especialidad de Química y egresados del Instituto Universitario Pedagógico de Caracas. Su desempeño laboral se enmarca en la Unidad Educativa José Antonio Caro ubicado en Catia, Municipio Libertador de la ciudad de Caracas. Valga esta información para hacer notar la igualdad etnográfica de los autores en cuanto a su nacionalidad, ámbitos de estudio y de trabajo, así como también de posibilidades de desarrollo socioeconómico individual en equidad de condiciones, categorías éstas que pueden 
facilitar el entendimiento y la comprensión del discurso o, mejor dicho, la intención comunicativa del discurso.

El texto elaborado por estos autores se encuentra integrado por 182 páginas, divididas en 9 capítulos conformados por 14 unidades temáticas en consonancia con lo establecido en la Programa Oficial vigente emitido por el Ministerio del Poder Popular para la Educación venezolana en el nivel de $4^{\circ}$ año de EMG (como se mencionó anteriormente) en la asignatura de Química, específicamente el tema 7 que corresponde al trabajo de Soluciones. Esto no quiere decir que los otros temas no sean relevantes sino, como se describió anteriormente, lo que corresponde a Soluciones está presente en la asignatura en todos los niveles de estudio.

El propósito en la elección de este tema se fundamenta en que es pilar fundamental en la enseñanza de la Química en EMG por ser común tanto en el $3^{\circ}$ año como en este que se estudia. La asimilación y acomodación del contenido conceptual y procedimental de este tema en la estructura cognitiva del estudiante define su prosecución escolar. En resumen, el tema de estudio debe ser trabajado de manera minuciosa, y el docente debe ayudarse con múltiples estrategias y actividades para el alcance de los objetivos planteados y el asentamiento de los respectivos contenidos.

El reconocimiento del discurso utilizado en el texto escolar que se está tratando debe ayudar a enfatizar aspectos que pudiesen presentarse como debilidades para que así se refuercen ideas durante el desarrollo de la actividad de aula, así como también se posibilita que el maestro adecúe su discurso con el del texto y transitivamente con la audiencia con la que éste interactúa en la búsqueda de un equilibrio que conforme una tríada didáctica.

Por cuestiones de extensión y profundidad, el análisis discursivo que pretende este ensayo corresponde, únicamente, al que se extraiga de la categoría de Interacción del Discurso Escrito, entre el escritor y el lector. Bolívar (1998), describe la interacción como: "una negociación de algún tipo en la que se espera un resultado" (p.69), y aplicando esto al discurso puede ser entendido como: "oraciones que interactúan con textos, textos que interactúan con lectores, pero rara vez escritores que interactúan con lectores" buscando esencialmente la descripción del texto mismo.

En concordancia con el párrafo anterior, el modelo en el cual se apoya este análisis corresponde al Interrelaciona propuesto por Bolívar (1998) y definido por la autora como un modelo que "explica mejor algunos aspectos fundamentales de la interacción escrita" y en este sentido se enfoca en la interacción que se produce entre el escritor y el lector a quien se le dirige el texto, en este caso al alumno por medio del texto escolar. 
Para lleva a cabo la aproximación se utilizarán dos categorías, a saber: a) categorías iniciales del discurso y b) planos del discurso.

En cuanto a las categorías iniciales del discurso que recoge el texto están presentes: a) la interacción social, ya que los individuos no se encuentras aislados sino en sociedad en donde se crean los significados. b) Participantes y por ello hay interacción, en este caso se busca la interacción escritor-lector y, c) el texto y su forma, estilo, gramática, composición, contenido entre otras, y es posible reconocer de éste lo siguiente:

- El texto está compuesto por oraciones largas y semánticamente complejas lo que lo transforma en un contenido de difícil compresión por un uso excesivo del lenguaje técnico científico químico.

- En ciertas oraciones del tema escogido hay problemas en la coherencia, concordancia y cohesión (ver ejemplo 1).

- El texto no parece dirigido a lectores en formación o los llamados por Bolívar (ob.cit) lectores generales, sino más bien a lectores óptimos, siendo éstos últimos para quienes el texto resulta más efectivo (por el manejo de conocimientos previos en el tema). Cabe destacar que el lector usuario del texto escolar, en su mayoría, no posee conocimientos formales ya que se ubican apenas en el $4^{\circ}$ año de EMG, por lo que la información bajo esta estructura les resulta de difícil entendimiento y asimilación.

Ejemplo 1: Durante los procesos de disolución en el ión positivo atrae al extremo negativo de las moléculas del disolvente polar, en tanto el ión negativo atrae al extremo positivo, al formarse estos enlaces, se dice que los iones están solvatados, si el disolvente es agua se utiliza el término hidratado y el fenómeno se llama Hidratación. (Serrano y Sanella, 1989:123)

Observación: Cuando se prepara una solución en el laboratorio se debe recordar que las cargas eléctricas de diferente signo se atraen (negativas y positivas) y cuando se le añade el solvente pueden ocurrir dos efectos: si el solvente no es agua en los enlaces se produce una solvatación (por solvente) y si el solvente es agua se produce una hidratación. (prefijo hidro = agua)

En lo que corresponde a los planos del discurso se deben identificar dos: a) prospectivo que refiere a la interacción entre los participantes, bien sea entre ellos mismos o entre ellos y el entorno social $y, b)$ retrospectivo que corresponde a la interacción que se da entre el lector y el discurso del texto (Bolívar, ob.cit). Tomando en cuenta lo anterior se puede decir que: 
- En el texto sólo se muestran los efectos y son muy escasas las causas de los procesos químicos. Una presunta espontaneidad procedimental.

- La descripción de los procesos químicos dinámicos que ocurren en el mundo real se vuelven estáticos lo que supone una visión positivista que pretende dar al menos, así sea forzada, una explicación a cada fenómeno. Asimismo, los ejemplos en el discurso son lejanos de la cotidianidad lo que dificulta la comparación por parte del lector. (ver ejemplo 2)

- Como consecuencia de lo anterior no hay cabida para lo probable ni para el cambio de los fenómenos naturales por lo que no hay estimulación a la incertidumbre.

- Hay un uso predominante de “¿qué?” y “¿cuáles?” en las actividades y problemas propuestos.

Ejemplo 2: Cuando se disuelve un líquido, el disolvente es el que esté en mayor cantidad, por ejemplo, si se prepara una solución de $10 \mathrm{ml}$ de Propanol liq y $50 \mathrm{ml}$ de agua, el disolvente es el agua y el soluto es el Propanol, si se invierten las cantidades el disolvente sería el Propanol. (Serrano y Sanella, 1989:122)

Observación: a este nivel educativo el estudiante no conoce aun la química orgánica de donde deriva el compuesto propanol, por lo que se recomienda el uso de soluciones cotidianas como pueden ser el Gatorade ${ }^{\circledR}$, Nestea $₫$ o la naranjada pasteurizada.

A partir de lo anteriormente descrito, tanto en las categorías iniciales del discurso como en los planos del discurso es posible vislumbrar algunas de las dificultades que se le presentan a los estudiantes por el uso de textos de excelente calidad y cantidad de información pero para lectores óptimos y no para esta audiencia: lectores en formación. Por ello, a veces no debe extrañar al docente que el alumno no construya un texto escrito coherente con el contenido que se le presente, consecuencia lógica de lo que se intentó demostrar. Ante esta dificultad es recomendable el manejo de criterios de legibilidad de textos.

Este atrevimiento a construir una aproximación de análisis discursivo debe motivar a profundizar en el tema y en la elaboración de textos escolares que sean puente entre cotidianeidad y la ciencia formal, valiéndose de herramientas múltiples y pertinentes, trasposiciones didácticas y tecnología de la información y la comunicación (TIC), mejoramiento de la vigencia de la información y toma de casos prácticos que llamen la atención del lector, que lo motiven y no que le creen barreras cognitivas que rechacen su lectura o que simplemente la acepte sin criterio ni procesos cognitivos implicados, que solo lo memorice sin cuestionamiento y sin el alcance de nuevas zonas de desarrollo.

\section{Referencias}


BOLÍVAR, A.; (1998) "Discurso e interacción en el texto escrito" Universidad Central de Venezuela, pp. 63-73; 103-117. Consejo de Desarrollo Científico y Humanístico: Caracas

CONSTANTINO, G.; (2002) "Estrategias espaciales de aprendizaje y enfoques de análisis del discurso: un estudio comparativo" Conicet: Buenos Aires.

RAMÍREZ, T.; (2003) "El texto escolar: una línea de investigación en educación" Revista pedagógica, vol 24, № 70, pp. 273-292. ISSN: 0798-9702.

SERRANO, M. Y Sanella, J.; (1989) “Química”, pp. 121-126, Larense: Caracas.

SILVA, O.; (1997) "El estudio del discurso en el camino de Teun van Djik" Revista Frontera, № 16, pp. 97-106. Universidad de la Frontera, Temuco. 